\title{
Association of Complete Blood Count Parameters with Gestational Diabetes Mellitus
}

\author{
Zehra VURAL YILMAZ¹, Elif AKKAŞ YILMAZ1, Bilal İÇER', Tuncay KÜÇÜKÖZKAN1 \\ Ankara, Turkey
}

\begin{abstract}
OBJECTIVE: The aim of this study is to evaluate the relationship between hematological changes in early pregnancy using complete blood count parameters and gestational diabetes mellitus.

STUDY DESIGN: One hundred pregnant with gestational diabetes mellitus and one hundred healthy pregnant were included in the study. Blood samples for routine complete blood count parameters in first trimester of pregnancy were analyzed.

RESULTS: In the gestational diabetes mellitus group white blood cell, platelet count, neutrophil and lymphocyte count, mean platelet volume, red cell distribution width were significantly higher than control group. However, there was no significant difference between groups with regard to neutrophil to lymphocyte ratio and platelet to lymphocyte ratio levels. In binary logistic regression analysis; first trimester mean platelet volume and red cell distribution width values were found to be independently associated with diagnosis of gestational diabetes mellitus.
\end{abstract}

CONCLUSION: This study demonstrates that hematological parameters in first trimester of pregnancy are closely associated with gestational diabetes mellitus. The parameters that are routinely and automatically calculated in complete blood count; may be used to predict gestational diabetes mellitus.

Keywords: Gestational diabetes, Prediction, Complete blood count

Gynecol Obstet Reprod Med 2017;23(2):65-69

\section{Introduction}

Gestational diabetes mellitus (GDM) is defined as the glucose intolerance that results in hyperglycemia of variable severity, which is first recognized in pregnancy. It is seen in 3-10 \% of all pregnancies (1). GDM increases the risk of perinatal complications and predisposes the newborn to risk of macrosomia, shoulder dystocia and hypoglycemia (2). These offspring have increased risk of diabetes in future (3).

Increased proinflammatory and acute phase proteins with increased immune cells in healthy subjects are defined as

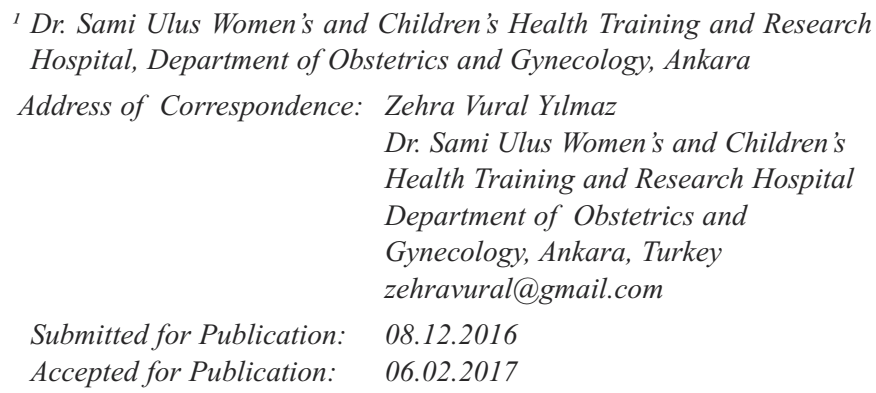

\begin{tabular}{|c|c|}
\hline & Access this article online \\
\hline $\begin{array}{c}\text { Quick Response Code: } \\
\text { 물. }\end{array}$ & Website: www.gorm.com.tr \\
\cline { 2 - 3 } & DOI:10.201613/GORM.2016.649 \\
\hline
\end{tabular}

How to cite this article: Vural Yllmaz Z. Akkas Yllmaz E. İçer B. Küçüközkan T. Association of Complete Blood Count Parameters with Gestational Diabetes Mellitus. Gynecol Obstet Reprod Med 2017;23(2):65-9 chronic subclinical inflammation $(4,5)$. In current studies chronic subclinical inflammation is emphasized in pathogenesis of Tip 2 DM, CVD and MS (6). Many biochemical and hematological markers are used to measure systemic inflammation. White blood cell count (WBC) in complete blood count $(\mathrm{CBC})$ test is the mostly used inflammatory marker in many diseases. However; in recent years there are studies proposing that the other hematological indices such as red cell distribution width (RDW), Mean platelet volume (MPV) and blood cell subtype ratios as platelet to lymphocyte ratio (PLR) and neutrophil to lymphocyte ratio (NLR) can be used as an inflammation parameter in different type of diseases (7). In the present study we aimed to investigate if hematological indices that are simple, easily and automatically calculated in a routine $\mathrm{CBC}$ test in first trimester of pregnancy have any value in the prediction of gestational diabetes.

\section{Material Method}

This retrospective case-control study was conducted at Women's Health Education and Research Hospital, a tertiary center in Ankara, Turkey. The study group consisted of 100 women who delivered in our hospital with a diagnosis of GDM. One hundred healthy pregnant women matched for maternal age and without any pregnancy complication and chronic systemic disease (endocrinological, urogenital, cardiovascular, gastrointestinal, immunological, or oncological) within the same time were recruited as the control group. All 
pregnant women included in this study were screened for GDM using a 50-g glucose challenge test (GCT) between 24 -28 week of gestation. $100 \mathrm{~g}$ oral glucose tolerance test (OGTT) was applied to pregnant women when 1st hour glucose level is $140 \mathrm{mg} / \mathrm{dL}$ or more. Pregnant with two or more abnormal values were diagnosed as GDM using Carpenter and Coustan guidelines. The demographic data including maternal age, gravidity, parity, pre-pregnancy weight and weight gain during pregnancy, gestational week at birth, fetal birth weight and Apgar score of the newborn was obtained from patient records. Hematological indices of routine CBC parameters in first trimester of pregnancy at first visit such as Hemoglobin $(\mathrm{Hb}), \mathrm{WBC}$, platelet count, RDW, MPV, neutrophil and lymphocyte values, fasting and 1 hour glucose level after GCT of all women in study were obtained from medical records. NLR and PLR values were calculated by dividing the absolute neutrophil and platelet count by the absolute lymphocyte count.

Gestational age was determined based on the first day of the last menstrual period (LMP) and first trimester ultrasonographic measurement of the crown-rump length (CRL). If the patient was not sure of her LMP, dating was based on ultrasound estimates by using the earliest CRL measurement during the first trimester. If ultrasound dating differed from LMP dating by more than seven days, the gestational age was changed according to ultrasound dating. Blood samples for routine $\mathrm{CBC}$ were all taken during the first visit at $6-13+6$ weeks of gestation. All CBC analyses were performed in the central hematology laboratory of our hospital within two hours of collecting the blood samples. The patients were classified as pregnant with GDM (group 1) and control (group 2).

The data were analyzed using the Statistical Package for Social Sciences, Windows version 20.0 (SPSS, Chicago, IL, USA). Descriptive statistics were expressed as mean and standard deviation for numerical variables. Normality of the data distribution was assessed with the Kolmogorov-Smirnov test. Statistical significant differences between the groups were de- termined by Mann-Whitney U test. Associations between the variables were explored using the Spearman's correlation coefficients. Binary logistic regression analysis was also performed to define variables associated with gestational diabetes in whole group. A p value less than 0.05 were considered significant.

\section{Results}

In total of 200 pregnant (100 control and 100 pregnant with GDM) were included to our study. There were no statistically significant differences between groups according to age, and body mass index (BMI). Women with GDM had higher gravidity and parity than control group. $(\mathrm{p}=0.021$, $\mathrm{p}=0.036$, respectively). Neonatal birth weight was significantly higher in GDM group but there was no difference between groups in terms of APGAR scores. Clinical and demographic characteristics of study group are shown in table 1 .

The mean WBC, platelet, neutrophil and lymphocyte count in pregnant with GDM were higher than healthy pregnant $(p=0.002, p=0.002, p=0.011$, and $p=0.026$, respectively). The mean MPV and RDW levels in GDM group were also higher than control group $(\mathrm{p}=0.001$ and $\mathrm{p}=0.015$, respectively). But there was no significant difference between groups with regard to NLR and PLR levels. Comparison of the hematological indices of study population is shown in table 2 .

In correlation analyses; Fasting blood glucose (FBG) level was correlated with $\mathrm{MCV}(\mathrm{r}=-0.18, \mathrm{p}=0.011)$ and $\mathrm{MPV}$ $(\mathrm{r}=0.22, \mathrm{p}=0.002)$. First hour glucose level after GCT was correlated with WBC $(\mathrm{r}=-0.258, \mathrm{p}=0.0002)$; $\mathrm{MCV}(\mathrm{r}=-0.258$, $\mathrm{p}=0.0002) ; \operatorname{MPV}(\mathrm{r}=0.275, \mathrm{p}=0.0008)$ and $\operatorname{RDW}(\mathrm{r}=-0.23$, $\mathrm{p}=0.001$ ).

Binary logistic regression analysis was performed to define the variables associated with diagnosis of GDM and CBC parameters and MPV and RDW were found to be independently associated with diagnosis of GDM (Table 3).

Table 1: Comparison of demographic and clinical characteristics of gestational diabetes mellitus (Group 1) and control (Group 2)

\begin{tabular}{|c|c|c|c|c|c|}
\hline \multirow{2}{*}{ Variables } & \multicolumn{2}{|c|}{ Group $1(n=100)$} & \multicolumn{2}{|c|}{ Group $2(n=100)$} & \multirow{2}{*}{$\begin{array}{c}p \\
\text { value }\end{array}$} \\
\hline & Mean & SD & Mean & SD & \\
\hline Maternal Age & 31.07 & 5.11 & 30.27 & 5.41 & 0.27 \\
\hline Gravidity & 2.79 & 1.22 & 2.40 & 1.18 & $0.021^{*}$ \\
\hline Parity & 1.46 & 0.91 & 1.19 & 1.02 & $0.036^{*}$ \\
\hline Miscarriage & 0.32 & 0.67 & 0.45 & 0.21 & 0.400 \\
\hline $\operatorname{BMI}\left(\mathrm{kg} / \mathrm{m}^{2}\right)$ & 24.4 & 2.3 & 23.8 & 3.2 & 0.8 \\
\hline Weight gain during pregnancy $(\mathrm{kg})$ & 11.47 & 4.74 & 11.79 & 3.16 & 0.262 \\
\hline Gestational Age at delivery (weeks) & 38.68 & 1.02 & 38.74 & 1.32 & 0.284 \\
\hline Birthweight (grams) & 3530 & 406 & 3215 & 430 & $0.001^{*}$ \\
\hline Apgar 1 score & 8.70 & 0.68 & 8.77 & 0.60 & 0.468 \\
\hline Apgar 5 score & 9.79 & 0.47 & 9.71 & 0.54 & 0.297 \\
\hline
\end{tabular}


Table 2: Comparison of the hematological indices of gestational diabetes mellitus (Group 1) and control (Group 2)

\begin{tabular}{|c|c|c|c|c|c|}
\hline \multirow{2}{*}{ Variables } & \multicolumn{2}{|c|}{ Group $1(n=100)$} & \multicolumn{2}{|c|}{ Group $2(n=100)$} & \multirow{2}{*}{$\begin{array}{c}p \\
\text { value }\end{array}$} \\
\hline & Mean & SD & Mean & SD & \\
\hline WBC count, $\left(\times 10^{3} / \mathrm{mm}^{3}\right)$ & 9.06 & 2.02 & 8.18 & 2.37 & $0.002^{*}$ \\
\hline $\mathrm{Hb}(\mathrm{gr} / \mathrm{dL})$ & 12.3 & 1.0 & 12.2 & 1.1 & 0.143 \\
\hline Platelet count $\left(\times 10^{3} / \mathrm{mm}^{3}\right)$ & 270.6 & 57.1 & 245.7 & 56.9 & $0.002^{*}$ \\
\hline Neutrophil count $\left(\times 10^{3} / \mathrm{mm}^{3}\right)$ & 5.26 & 1.72 & 5.72 & 1.98 & $0.011^{*}$ \\
\hline Lymphocyte count $\left(\times 10^{3} / \mathrm{mm}^{3}\right)$ & 2.01 & 0.56 & 1.84 & 0.55 & $0.026^{*}$ \\
\hline NLR & 3.31 & 1.13 & 3.31 & 1.57 & 0.307 \\
\hline PLR & 141.6 & 39.8 & 140.4 & 40.5 & 0.826 \\
\hline RDW & 15.0 & 1.5 & 14.4 & 1.3 & $0.015^{\star}$ \\
\hline MPV & 9.69 & 1.32 & 8.81 & 1.11 & $0.001^{*}$ \\
\hline $\mathrm{FBG}(\mathrm{mg} / \mathrm{dL})$ & 89.9 & 19.5 & 76.7 & 7.1 & $0.001^{*}$ \\
\hline $50-\mathrm{g} \mathrm{GCT}(\mathrm{mg} / \mathrm{dL})$ & 188.1 & 20.1 & 122.4 & 2.5 & $0.001^{*}$ \\
\hline
\end{tabular}

Data expressed as mean and SD: Standard deviation, WBC: White blood cell, Hb: Hemoglobin, NLR: Neutrophil lymphocyte ratio, PLR: Platelet lymphocyte ratio, RDW: Red cell distribution width, MPV: Mean platelet volume, FBG: Fasting blood glucose, GCT: Glucose challenge test, *: Indicates statistical significance

Table 3: Odds ratios for developing gestational diabetes mellitus

\begin{tabular}{lc|c|c|c}
\hline & & \multicolumn{2}{|c|}{$95 \%$ confidence interval } & \\
\hline OR & Minimum & Maximum & $p^{*}$ \\
\hline MPV & 2.007 & 1.492 & 2.700 & $0.001^{*}$ \\
RDW & 1.281 & 1.020 & 1.610 & $0.033^{*}$ \\
PLR & 1.008 & 0.998 & 1.018 & 0.101 \\
\\
\hline
\end{tabular}

OR: Odds ratio, MPV: Mean platelet volume, RDW: Red cell distribution width, PLR: Platelet lymphocyte ratio, NLR: Neutrophil lymphocyte ratio,*: Indicates statistical significance

\section{Discussion}

In the present study, we showed that several hematological parameters (WBC, MPV, RDW, neutrophil, lymphocyte and platelet count) were significantly higher in pregnant who developed GDM later. We also found that GDM was positively correlated with fasting blood glucose, WBC, platelet count, RDW and MPV. Elevated MPV and RDW values in first trimester were found to be independent predictors of GDM.

Increased placental hormones (human chorionic somatomammotropin, cortisol, progesterone) especially beginning in the second trimester of pregnancy cause insulin resistance and hyperglycemia in pregnancy (8). Insufficiency of insulin release to compensate this pregnancy induced insulin resistance is defined as GDM (9). In recent years subclinical inflammation is also associated with insulin resistance $(7,10$, 11). Elevated cytokines in inflammation impair beta-cell function and can affect insulin signaling directly $(10,12)$. Inflammation markers including CRP and IL 6 are found to be increased in DM and also have been shown to predict the future diabetes risk (6). The associations between inflammation, obesity and GDM are also well known. Adipose tissue regulates insulin resistance by secreting cytokines and responsible for pathogenesis of insulin resistance in type $2 \mathrm{DM}$, MS and also in GDM. In our study we demonstrated that; pregnant with GDM were heavier than healthy pregnant in pre-pregnancy period, but weight gain during pregnancy were similar between groups. This could be due to glycemic control and attention to diet and weight gain in GDM patients.

Despite advances in the understanding of pathogenesis of GDM, there is not yet a method and an ideal single biomarker that predicts the disease in first trimester. Early prediction of disease to identify pregnant at risk is important for primary prevention of this disease and improve the outcome for mother and baby (13). Several studies have explored the diagnostic value of hematological indices in gestational diabetes in second and third trimester but there are few studies with these parameters in first trimester.

White blood cell is a classical inflammatory marker and elevated WBC is associated with impaired glucose metabolism, insulin resistance and DM. Pattanathaiyanon et al, demonstrated that increased WBC count in early pregnancy had a significant rate of GDM than having normal WBC count (14). Likewise Wolf et al reported that WBC count greater than 9100 cells $/ \mu \mathrm{L}$ in early pregnancy was significantly associated with the risk of GDM (15). Other than WBC blood cell subtype ratios, likewise NLR and PLR are used as diagnostic and prog- 
nostic marker in diseases related to chronic low-grade inflammation in recent studies $(4,5)$. Yilmaz et al found that women with GDM have higher NLR in second trimester of pregnancy (16); Demirtas et al showed that NLR and PLR were significantly higher in non-pregnant diabetic patients than controls (7). Consistent with literature, WBC were higher in GDM pregnant group in the first trimester of pregnancy in our study. Whereas NLR and PLR values were similar between the two groups.

Beside the thromboembolic disorders platelet indices are associated with inflammation and disease activity of inflammatory disorders. Platelet hyper aggregation is the most common change in platelet behavior in diabetes and hyper aggregation in platelets was reported in patients with both type 1 and type 2 DM $(17,18)$. Enhanced platelet protein glycation may cause increased platelet activity in diabetic patients (19). MPV shows average size of a platelet and a parameter that reflects platelet activation and alteration in the homeostasis and coagulation system (20). The potential explanation of this phenomenon is larger platelets are more active $(20,21)$. Higher MPV levels have been reported in patients with DM and it is related with diabetic complications (22). In a study; evaluating the MPV in GDM, Bozkurt et al. found higher MPV levels in pregnant with GDM in third trimester (23) and this finding is also supported by Baldane et al. in second trimester of pregnancy (24). However in a few case-control studies no significant difference was found between GDM and control groups in terms of MPV count $(25,26)$.

Red cell distribution width is the variability in size of circulating red blood cells and increased RDW is associated with hypertension, CVD and MS (27). Chronic inflammation could cause RDW level elevation and elevated RDW may reflect a status of high inflammation and oxidative stress (27). Tripolino et al. demonstrated that RDW predicts the glucose metabolism disturbance after 75 -g oral glucose tolerance test in non-pregnant patients (28). However; Erdoğan et al found no significant difference between healthy pregnant and pregnant with GDM in terms of RDW levels (25). We found significantly higher RDW and MPV levels in first trimester in pregnant women who developed gestational diabetes later. To the best of our knowledge this is the first study that showed relationship between RDW and MPV levels in early pregnancy and latter diagnosis of gestational diabetes.

The first trimester is becoming an important period for potential lifestyle or pharmacological interventions to reduce the risk of adverse maternal and fetal outcomes in GDM and there are many studies to analyze serum biomarkers either alone or in conjunction with other maternal risk factors to predict GDM in first trimester. Mashiah et al. reported that fasting plasma glucose levels in the first trimester between 4.4 and 4.7 $\mathrm{mmol} / \mathrm{l}$ had sensitivities of between 55 and $75 \%$ and specificities of 52 and $75 \%$ for the prediction of GDM (29). Lower sex hormone binding globulin (SHBG) (30), higher serum testosterone with dehydroepiandrosterone sulfate (31) and lower adiponectin concentrations (32) measured in early pregnancy have also been linked to the development of GDM in other studies. However; despite the studies there is not yet a method and single biomarker that predicts the disease accurately in the first trimester $(33,34)$.

As a result; $\mathrm{CBC}$ is a part of routine blood tests to evaluate pregnant basic health status in first trimester. Measuring CBC parameters are fast, easily applicable and they can be used to predict GDM in the early pregnancy. However, largescale and prospective studies are needed to evaluate these parameters role in predicting GDM and to say these parameters could replace the screening tests during the second trimester.

\section{References}

1. Hartling L, Dryden DM, Guthrie A, Muise M, Vandermeer $\mathrm{B}$, Donovan L. Benefits and harms of treating gestational diabetes mellitus: a systematic review and metaanalysis for the U.S. Preventive Services Task Force and the National Institutes of Health Office of Medical Applications of Research. Ann Intern Med 2013 Jul 16;159(2):123-9.

2. Yogev Y, Visser GH. Obesity, gestational diabetes and pregnancy outcome. Semin Fetal Neonatal Med 2009 Apr; 14(2):77-84.

3. Clausen TD, Mathiesen ER, Hansen T, Pedersen O, Jensen $\mathrm{DM}$, Lauenborg J et al. High prevalence of type 2 diabetes and pre-diabetes in adult offspring of women with gestational diabetes mellitus or type 1 diabetes: the role of intrauterine hyperglycemia. Diabetes Care 2008 Feb;31(2): 340-6.

4. Fowler AJ, Agha RA. Neutrophil/lymphocyte ratio is related to the severity of coronary artery disease and clinical outcome in patients undergoing angiography-the growing versatility of NLR. Atherosclerosis 2013 May;228(1):44-5.

5. Guthrie GJ, Charles KA, Roxburgh CS, Horgan PG, Mc Millan DC, Clarke SJ. The systemic inflammation-based neutrophil-lymphocyte ratio: experience in patients with cancer. Crit Rev Oncol Haematol 2013 Oct; 88(1):218-30.

6. Pradhan AD, Manson JE, Rifai N, Buring JE, Ridker PM. C-reactive protein, interleukin 6, and risk of developing type 2 diabetes mellitus. JAMA 2001 Jul 18;286(3):32734.

7. Demirtas L, Degirmenci H, Akbas ME, Ozcicek A, Timuroglu A, Gurel A. et al. Association of hematological indices with diabetes, impaired glucose regulation and microvascular complications of diabetes. Int J Clin Exp Med 2015 Jul 15;8(7):11420-7.

8. Di Cianni G, Miccoli R, Volpe L, Lencioni C, Del Prato $\mathrm{S}$. Intermediate metabolism in normal pregnancy and in gestational diabetes. Diabetes Metab Res Rev 2003 JulAug;19(4):259-70.

9. Metzger BE, Buchanan TA, Coustan DR, De Leiva A, 
Dunger DB, Hadden DR. et al. Summary and recommendations of the Fifth International Workshop- Conference on Gestational Diabetes Mellitus. Diabetes Care 2007 Jul; 30 Suppl 2:251-60.

10. Das A, Mukhopadhyay S. The evil axis of obesity, inflammation and type-2 diabetes. Endocr Metab Immune Disord Drug Targets 2011 Mar;11(1):23-31.

11. Hotamisligil GS. Inflammation and metabolic disorders. Nature 2006 Dec 14; 444(7121):860-7.

12. Agrawal NK, Kant S. Targeting inflammation in diabetes: Newer therapeutic options. World J Diabetes 2014 Oct 15; 5(5):697-710.

13. Richardson AC, Carpenter MW. Inflammatory mediators in gestational diabetes mellitus. Obstet Gynecol Clin North Am 2007;34:213-44.

14. Pattanathaiyanon P, Phaloprakarn C, Tangjitgamol S. Comparison of gestational diabetes mellitus rates in women with increased and normal white blood cell counts in early pregnancy. J Obstet Gynaecol 2014; 40:976-82.

15. Wolf M, Sandler L, Hsu K, Vossen-Smirnakis K, Ecker JL, Thadhani R. First-trimester C-reactive protein and subsequent gestational diabetes. Diabetes Care 2003;26: 819-24.

16. Yilmaz H, Celik HT, Namuslu M, Inan O, Onaran Y, Karakurt F. et al. Benefits of the Neutrophil-to-Lymphocyte Ratio for the Prediction of Gestational Diabetes Mellitus in Pregnant Women. Exp Clin Endocrinol Diabetes 2014;122:39-43.

17. Hughes A, McVerry BA, Wilkinson L, Goldstone AH, Lewis D, Bloom A. Diabetes, a hypercoagulable state? Haemostatic variables in newly diagnosed type 2 diabetic patients. Acta Haematologica 1983;69(4):254-9.

18. Rosove MH, Frank HJ, Harwig SS. Plasma beta- thromboglobulin, platelet factor 4 , fibrinopeptide A, and other hemostatic functions during improved, short-term glycemic control in diabetes mellitus. Diabetes Care 1984 MarApr;7(2):174-9.

19. Watala C, Pluta J, Golanski J, Rozalski M, Czyz M, Trojanowski $Z$. et al. Increased protein glycation in diabetes mellitus is associated with decreased aspirin-mediated protein acetylation and reduced sensitivity of blood platelets to aspirin. J Mol Med (Berl) 2005 Feb; 83(2): 148-58.

20. Dundar O, Yoruk P, Tutuncu L, Erikci AA, Muhcu M, Ergur AR. et al. Longitudinal study of platelet size changes in gestation and predictive power of elevated MPV in development of preeclampsia. Prenat Diagn 2008 Nov; 28(11):1052-6.

21. Kamath S, Blann AD, Lip GY. Platelet activation: assessment and quantification. Eur Heart J 2001 Sep;22(17): 1561-71.

22. Leader A, Pereg D, Lishner M. Are platelet volume indices of clinical use? A multidisciplinary review. Ann Med
2012 Dec;44(8):805-16.

23. Bozkurt N, Yilmaz E, Biri A, Taner Z, Himmetoğlu O. The mean platelet volume in gestational diabetes. J Thromb Thrombolysis 2006 Aug;22(1):51-4.

24. Baldane S, Ipekci SH, Kebapcilar A. Relationship Between Insulin Resistance and Mean Platelet Volume in Gestational Diabetes Mellitus. J Lab Physicians 2015 JulDec;7(2):112-5.

25. Erdoğan S, Ozdemir O, Doğan HO, Sezer S, Atalay CR, Meriç $\mathrm{F}$ et al. Liver enzymes, mean platelet volume, and red cell distribution width in gestational diabetes. Turk J Med Sci 2014;44(1):121-5.

26. Yin SM, Li YQ, Xie SF, Ma LP, Wu YD, Nie DN et al. Study on the variation of platelet function in pregnancy induced hypertension and gestational diabetes mellitus. Zhonghua Fu Chan Ke Za Zhi 2005 Jan;40(1):25-8.

27. Felker GM, Allen LA, Pocock SJ, Shaw LK, McMurray JJ, Pfeffer MA. et al. Red cell distribution width as a novel prognostic marker in heart failure: data from the CHARM Program and the Duke Databank. J Am Coll Cardiol 2007 Jul 3;50(1):40-7.

28. Tripolino C, Irace C, Carallo C, De Franceschi MS, Scavelli FB, Gnasso A . Red blood cell distribution width predicts two-hours plasma glucose levels during OGTT. Clin Hemorheol Microcirc 2016;62(1):63-9.

29. Riskin-Mashiah S, Damti A, Younes G, Auslender R. First trimester fasting hyperglycemia as a predictor for the development of gestational diabetes mellitus. Eur J Obstet Gynecol Reprod Biol 2010 Oct; 152(2):163-7.

30. Maged AM, Moety GA, Mostafa WA, Hamed DA. Comparative study between different biomarkers for early prediction of gestational diabetes mellitus. J MaternalFetal Neonatal Med 2014 Jul;27(11):1108-12.

31. Gozukara YM, Aytan H, Ertunc D, Tok EC, Demirtürk F, Şahin Ş. et al. Role of first trimester total testosterone in prediction of subsequent gestational diabetes mellitus. J Obstet Gynaecol Res 2015 Feb;41(2):193-8.

32. Lain KY, Daftary AR, Ness RB, Roberts JM. First trimester adipocytokine concentrations and risk of developing gestational diabetes later in pregnancy. Clin Endocrinol 2008 Sep;69(3):407-11.

33. Yeral MI, Ozgu-Erdinc AS, Uygur D, Seckin KD, Karsli MF, Danisman AN. Prediction of gestational diabetes mellitus in the first trimester, comparison of fasting plasma glucose, two-step and one-step methods: a prospective randomized controlled trial. Endocrine 2014;46(3):512-8.

34. Ozgu-Erdinc AS, Yilmaz S, Yeral MI, Seckin KD, Erkaya S, Danisman AN. Prediction of gestational diabetes mellitus in the first trimester: comparison of C-reactive protein, fasting plasma glucose, insulin and insulin sensitivity indices. J Matern Fetal Neonatal Med 2015;28(16):1957-62. 